\title{
Desenvolvimento de um Software para cálculo da densidade de nódulos de grafita em ferro fundido nodular através de Processamento Digital de Imagens
}

\section{Software development for ductile cast iron graphite nodules density calculation using Digital Image Processing}

\author{
Filipe de Macêdo Peixoto ${ }^{1}$, Elizângela de Souza Rebouças ${ }^{1}$, \\ Francisco Geilson de Lima Xavier ${ }^{2}$, Pedro Pedrosa Rebouças Filho ${ }^{2}$
}

\footnotetext{
${ }^{1}$ Grupo de Pesquisa em Sistemas Inteligentes (GPSI) - IFCE - CEP: 61925-315, Maracanaú, CE e-mail: filipebahia@gmail.com, elizangelareboucas@gmail.com

${ }^{2}$ Programa de Pós-Graduação em Energias Renováveis (PPGER) - IFCE - CEP: 61925-315, Maracanaú, CE e-mail: geilsonx@gmail.com, pedrosarf@ifce.edu.br
}

\section{RESUMO}

O presente trabalho tem como objetivo determinar o número de nódulos de grafita em amostra de ferro fundido nodular, de acordo com a norma NBR 6913, utilizando técnicas de processamento e análise de imagens digitais. Esta contagem determina propriedades mecânicas do ferro fundido nodular que são utilizados para projetos para aplicações na área. Deste modo, esta contagem é feita, tradicionalmente, de forma visual por um operador através do auxílio de um microscópio óptico. Com o objetivo de reduzir o tempo de contagem da quantidade de nódulos e eliminar o máximo possível de erros na contagem, foi desenvolvido um software, utilizando a Linguagem $\mathrm{C}$ e com auxílio da biblioteca OpenCV. Esta biblioteca é livre e agrupa técnicas otimizadas de Visão Computacional através de técnicas de Processamento Digital de Imagens. Foram utilizadas duas abordagens para contabilizar os nódulos, uma através do método Crescimento de Regiões e outra utilizando Watershed. Testes são realizados e comparados com o resultado obtido por seis especialistas utilizando a técnica visual tradicional visando avaliar os métodos propostos. Os resultados obtidos demonstram que os métodos podem ser incorporados a um sistema para cálculo do número de nódulos em ferro fundido nodular. Ao fim deste trabalho, é possível confirmar a praticidade e a confiabilidade na contagem de nódulos utilizando o software desenvolvido, em comparação ao método tradicional de contagem, demonstrando sua importância para auxílio nesta área do conhecimento.

Palavras-chave: Processamento Digital de Imagens, OpenCV, ferro fundido, cálculo de nódulos de grafita.

\begin{abstract}
This study aims to determine the number of graphite nodules in ductile iron sample according to NBR 6913 and using techniques process and analysis in digital images. This count determines the mechanical properties of the nodular cast iron, which are used for project designs in the field. Therefore, an operator with the aid of an optical microscope does this count traditionally visually. Aiming to reduce the time of determining the amount of nodes and eliminate the maximum possible error in counting, a software was developed using the $\mathrm{C}$ language and with the help of the OpenCV library. This library is open source and incorporates optimized Computer Vision techniques. Two approaches were used to count the nodes, one by Region Growing and another using Watershed. Tests were performed and compared with the results obtained by six experts using traditional visual technique to evaluate the proposed methods. The results show that the methods can be incorporated into a system to calculate the number of nodules in nodular cast iron. At the end of this work, it is possible to confirm that the developed software is useful and reliable to nodule count. Therefore is demonstrated its importance to aid this knowledge area.
\end{abstract}

Keywords: Digital Image Processing, OpenCV, cast iron, calculation of graphite nodules. 


\section{INTRODUÇÃO}

As técnicas de processamento de imagens digitalizadas possuem diversas áreas de aplicações como, por exemplo, na automação de robôs [1], em sistemas de segurança [2] e na análise de materiais mecânicos [3] , que é o objeto de estudo deste trabalho.

Dentre os diversos tipos de análises de materiais por processamento digital de imagens, destaca-se a análise metalográfica das características do ferro fundido nodular. Para a realização desta análise faz-se necessária a verificação da quantidade de nódulos de grafita em suas amostras utilizando normas técnicas.

Essa análise é feita, tradicionalmente, de forma visual utilizando um microscópio óptico. Desse modo, torna-se subjetiva e enfadonha, gerando necessidade de automatizar este processo.

Neste sentido, este trabalho visa construir um Sistema de Visão Computacional (CVS), utilizando a biblioteca de código aberto OpenCV, capaz de quantificar nódulos de grafita em amostras de ferro fundido nodular.

Chiaverini [4] diz que "O Ferro Fundido é a liga ferro-carbono-silício, de teores de carbono geralmente acima de 2,0\%, em quantidade superior à que pode ser retida em solução sólida de austenita, de modo a resultar carbono parcialmente livre, na forma de veios ou lamelas de grafita".

Entre os fatores que influenciam na estrutura do ferro fundido, a velocidade de resfriamento e sua composição química são os que mais se destacam [5]. Outros fatores influentes são a inoculação e o superaquecimento.

A quantidade de grafita na estrutura dos ferros fundidos é de bastante importância no ponto de vista estrutural. Quanto maior a quantidade de grafita presente na microestrutura do ferro fundido, menor será sua resistência mecânica. Este fato se dá devido aos efeitos vazio, entalhe e distribuição.

O ferro fundido é classificado em alguns tipos, de acordo com a forma da grafita, com uma diferenciação adicional devido à estrutura da matriz metálica (que pode ser ferrítica, perlítica, ferrítico-perlítica, austenítica, martensítica), como pode ser visto na Figura 1, sendo que cada matriz originará propriedades diferentes e classes de material diferentes [6]. Ferros fundidos cinzento, branco, mesclado, maleável e nodular são alguns tipos de ferro fundido.

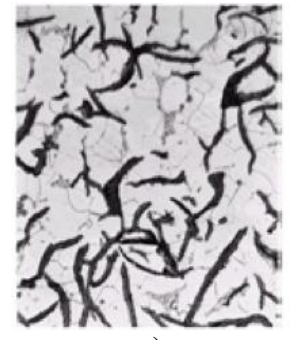

a)

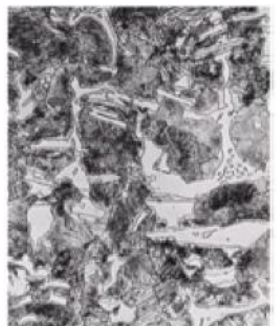

b)

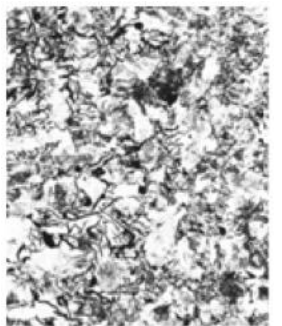

c)

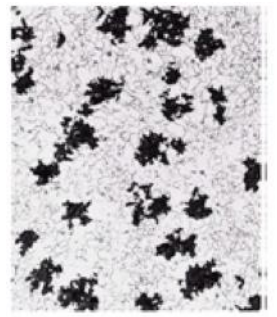

d)

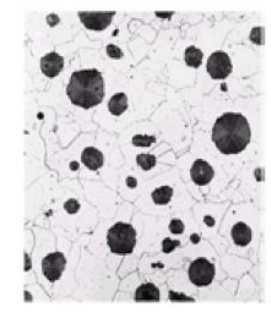

e)

Figura 1: Amostras de Ferros Fundidos: a) cinzento; b) branco; c) mesclado; d) maleável; e) nodular [ㅁ]

\section{MATERIAIS E MÉTODOS}

O ferro fundido nodular, objeto de estudo deste trabalho, é definido como uma liga Fe-C-Si em que o carbono encontra-se na forma de grafita esferoidal no estado bruto de fundição.

O ferro fundido nodular é conhecido por sua ductilidade, mas a vantagem mais importante tem sido seu alto módulo de elasticidade e resistência mecânica, em combinação com resistência a corrosão, fácil fundição e usinabilidade [7].

Este material substitui o ferro cinzento e o aço em variadas aplicações. Algumas dessas aplicações são as cambotas, sapatas e tambores de travões, diferenciais, rodas dentadas, válvulas, condutas de água e outros fluidos e lingoteiras, entre outros.

Deste modo, para cálculo de algumas destas propriedades, faz-se necessário a contagem dos nódulos de grafita em ferro fundido nodular utilizando a Norma Brasileira (NBR) 6913. Esta norma é utilizada como base no método proposto para cálculo automático utilizando imagens de metalografia. A norma NBR 6913, o sistema convencional e o método proposto são descritos a seguir. 


\subsection{NBR 6913 - Ferro fundido nodular e ferro fundido maleável - Contagem de nódulos de grafita}

Esta norma determina o procedimento de contagem de nódulos de grafita, em ferro fundido nodular e ferro fundido maleável, através da utilização de microscópio e corpo-de-prova de preferência não atacado quimicamente.

A densidade de nódulos de grafita possui a unidade nódulos $/ \mathrm{mm}^{2}$, e é determinada por

Densidade $=\frac{\left(\mathrm{NI}+\frac{\mathrm{NP}}{2}\right)}{\mathrm{S} \times \mathrm{n}} \times \mathrm{A}^{2}$,

em que $S$ é a área do retículo analisado, $A$ representa o aumento do microscópio em que a amostra está sendo analisada, $n$ é o número de amostras, $N I$ é o número de nódulos inteiros na região e $N P$ é o número de nódulos que estão parcialmente dentro da região analisada. Vale ressaltar que $N P$ considera os nódulos que estão completamente dentro da área analisada, enquanto $N I$ considera os nódulos que estão na fronteira da área analisada, possuindo parte dentro da região e parte fora.

A Figura 2 representa um modelo de retículo para determinação no número de nódulos.

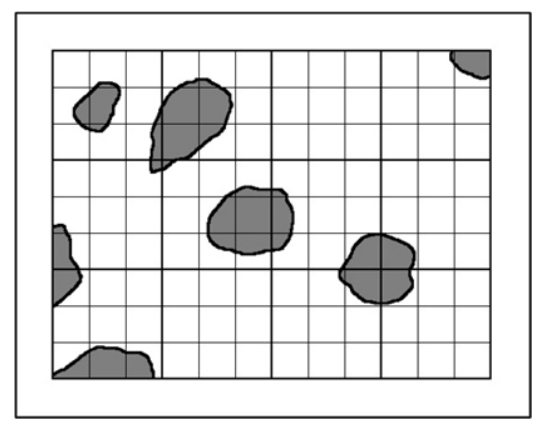

Figura 2: Modelo de retículo e determinação do número de nódulos projetados no retículo [8]

\subsection{Sistema de Visão Computacional Desenvolvido utilizando Watershed}

A Transformada de Watershed se baseia no fenômeno natural da enchente de relevos topográficos [9]. Para se compreender o método, deve-se imaginar a imagem como sendo um relevo topográfico visto de cima, como se uma foto de satélite desta região fosse capturada. Qualquer imagem Tom de Cinza pode ser considerada como uma superfície topográfica. Caso uma superfícies seja inundada, suas regiões de valores mínimos será a primeira à ser afetada, e a região inundada aumenta progressivamente, parando apenas quando encontrar outra região em crescimento. Por fim, têm-se a imagem dividida em dois grupos diferentes: Bacias hidrográficas e Linhas de bacias hidrográficas. A Figura 3 apresenta um exemplo de visualização desta metodologia.

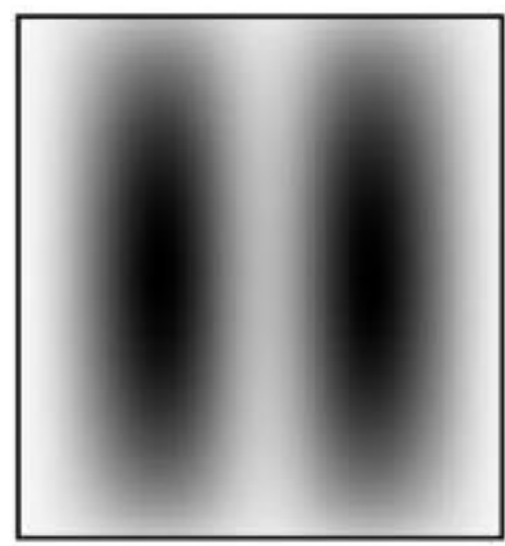

(a)

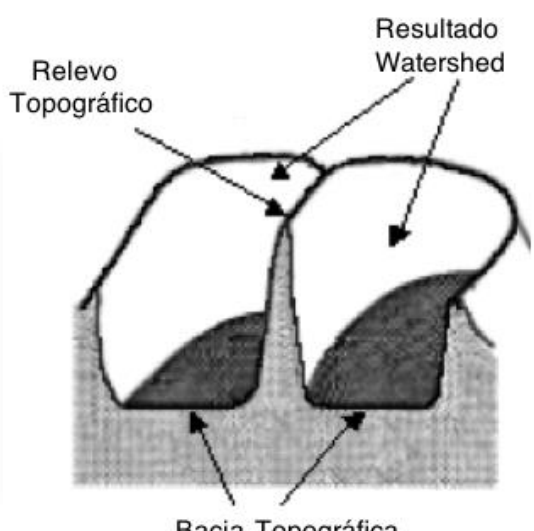

Bacia Topográfica (b)

Figura 3: Demonstração da teoria de watershed, sendo a) imagem em tom de cinza, b) demonstração topológica dos objetos de a), adaptado de [10]. 
As regiões mais escuras da Figura 3 representam os vales, e as regiões mais claras, as montanhas. Ao se inundar a região com água, os vales vão se enchendo e transformam-se em bacias. Conforme vão enchendo, bacias maiores vão se formando pelo encontro das águas. Nos topos das montanhas, onde as bacias se dividem, são formadas as linhas divisórias de água, ou watersheds. Ao chegar neste ponto a inundação para, e as watersheds separam as regiões segmentadas.

Ao aplicar essa transformação ao gradiente de imagem, as bacias hidrográficas devem teoricamente corresponder às regiões de nível de cinza homogêneas desta imagem, enquanto os gradientes serão utilizados como base para encontrar os objetos topográficos. Sendo assim, para determinar os nódulos de grafita com a transformada Watershed, na imagem tom de cinza é aplicado o operador gradiente de Canny. O resultado obtido nesta etapa é utilizado para identificar as bacias hidrográficas, que nesta aplicação são os nódulos de grafita. Estas etapas são apresentadas na Figura 4 em sequência, em que o resultado apresentado na Figura 4(c) é usado uma cor distinta para cada nódulo de grafita encontrado.

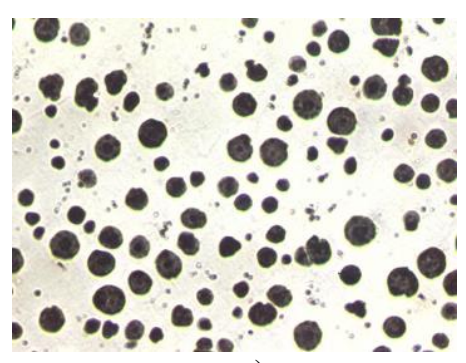

a)

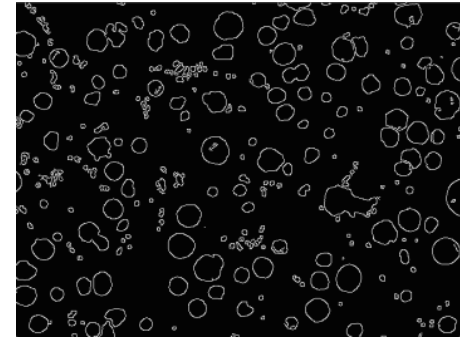

b)

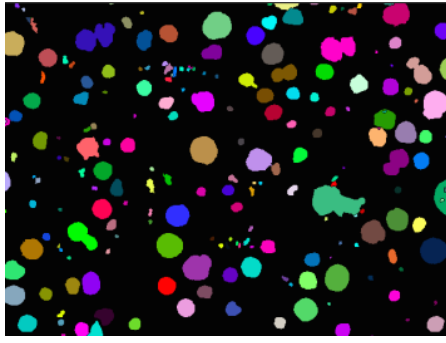

c)

Figura 4: Aplicação da Transformada Watershed no cálculo dos nódulos de grafita, sendo a) imagem em tom de cinza com nódulos de grafita, b) Gradiente de Canny de a), c) resultado da Transformada Watershed.

Após encontrar os nódulos, verifica-se se os mesmos estão nas bordas da imagem ou não, e caso esteja nas extremidades da imagem este é contabilizado como Nódulo Parcial (NP), os outros que estão inteiramente dentro da imagem são contabilizados como Nódulos Inteiros (NI).

\subsection{Sistema de Visão Computacional Desenvolvido utilizando Crescimento de Regiões}

Um sistema de PDI é dividido em cinco etapas de execução [11]. A aquisição de imagens consiste em obter a imagem através de um dispositivo de captura que em seguida digitaliza a imagem [11]. O pré-processamento busca melhorar a qualidade da imagem através da redução de ruídos ou aberrações e ajustes de brilho e contraste, reforçando o contorno dos objetos da imagem, retirando regiões ou tonalidades não desejadas ou então reduzindo distorções [11]. A fase de segmentação consiste em identificar e isolar as regiões de interesse na imagem digital [11]. Finalmente, o objetivo da extração de atributos é extrair informações da imagem que sejam úteis para seus devidos fins [12]. Uma ilustração das etapas pode se vista na Figura 5.

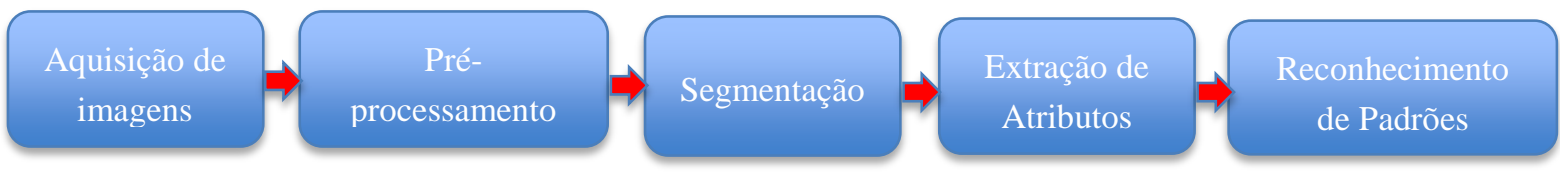

Figura 5: Etapas de um sistema de Visão Computacional Típico.

Seguindo as etapas apresentadas na Figura 5, tem-se que o Sistema de Visão Computacional (SVC) desenvolvido utilizando Crescimento de Regiões segue em sua execução o fluxograma apresentado na Figura 6.

Neste trabalho foi desenvolvido um software utilizando a Linguagem C++ através da ferramenta de programação Visual C++ 2010. Para a implementação destes métodos, este trabalho utiliza a biblioteca livre de Visão Computacional (OpenCV). Esta biblioteca de programação, de código aberto, desenvolvida pela Intel 
Corporation [13] que possui mais de 500 funções pode ser utilizada em diversas linguagens de programação, entretanto neste projeto é utilizada Linguagem C++ [14].

O início do algoritmo se dá através da abertura das imagens para que, posteriormente, seja realizado o processamento digital das mesmas. Vale ressaltar que neste trabalho, as imagens são adquiridas utilizando um microscópio óptico para capturar imagens de amostras de ferro fundido nodular preparadas por metalografia.

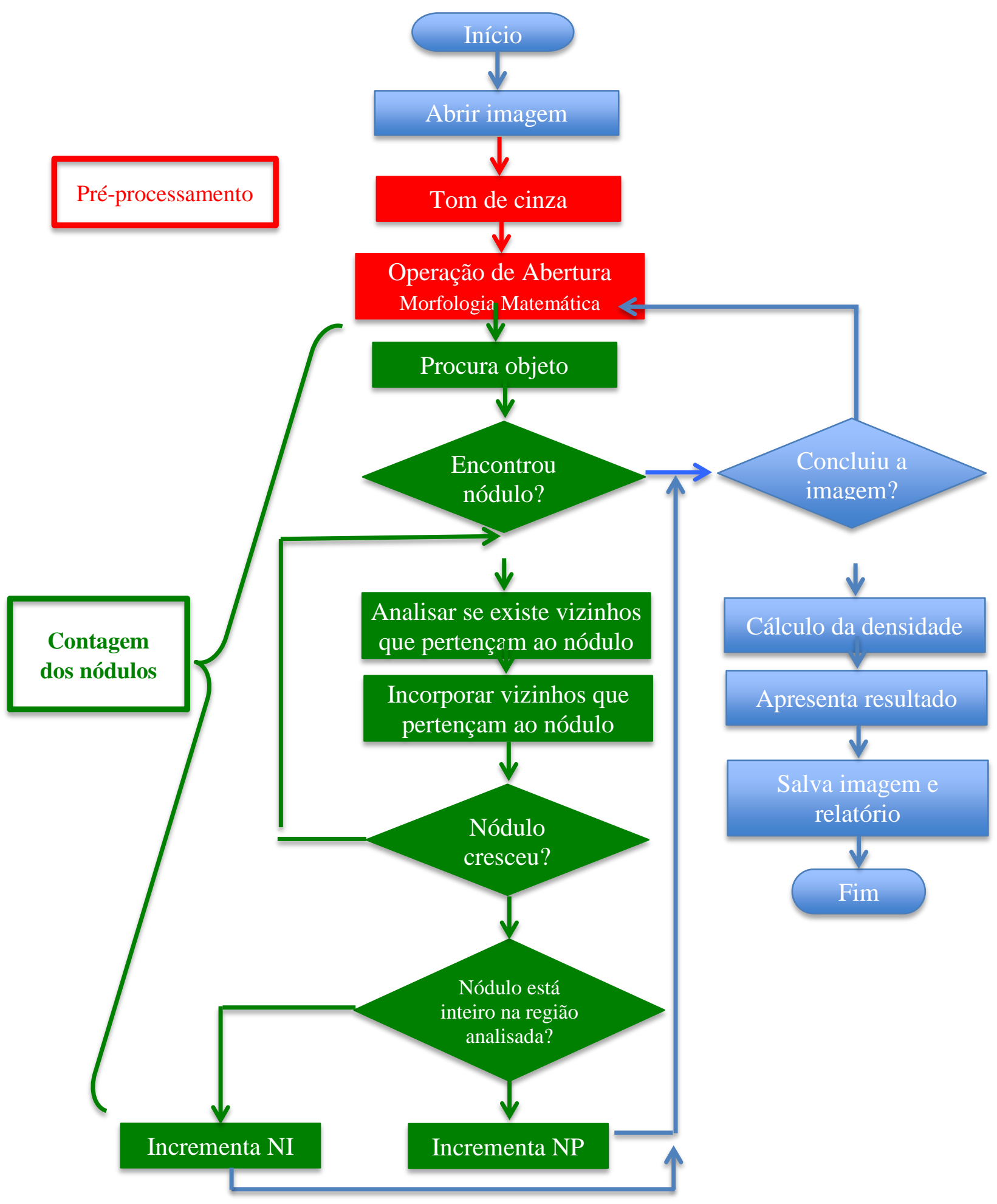

Figura 6: Fluxograma do software desenvolvido. 
Após a abertura das imagens são aplicados, em cada imagem, transformação para escalas de cinza e limiarização, conforme Figura 6, que corresponde a as etapas de pré-processamento. Pode-se descrever limiarização, matematicamente, como sendo uma técnica de PDI onde uma imagem de entrada de n níveis de cinza gera uma imagem de saída $g$, com um número de níveis de cinza menor que $n$ [11]. Normalmente, g apresenta dois níveis de cinza, onde $g(x, y)$ representa um pixel na coordenada $(x, y)$ da imagem $g$ conforme a equação

$g(x, y)= \begin{cases}1, & \text { se } f(x, y) \geq T \\ 0, & \text { se } f(x, y)<T\end{cases}$

Nesta equação, aos objetos a serem identificados atribui-se o valor 1 e ao fundo atribui-se o valor $0 . T$ representa o limiar, que significa um ponto ótimo entre valores de nível de cinza necessário para dividir a imagem em duas regiões ou em mais regiões. O limiar utilizado neste trabalho é definido de forma automática através do método de Ostu [11]. Esta técnica visa retirar falhas de luminosidade e tornar o fundo dos nódulos uniforme, funcionando como pré-processamento no SVC desenvolvido. A última técnica do préprocessamento é a técnica de Abertura da Morfologia Matemática [11], que retira objetos da imagem menores que o elemento estruturante usado, que neste trabalho foi utilizado $3 \times 3$.

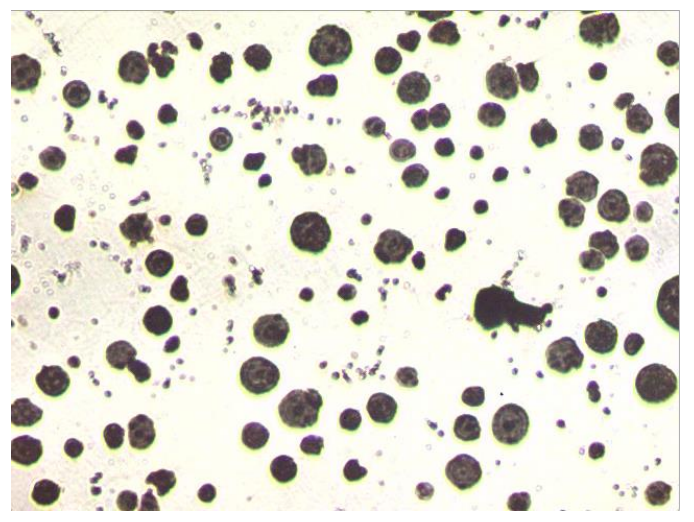

a)

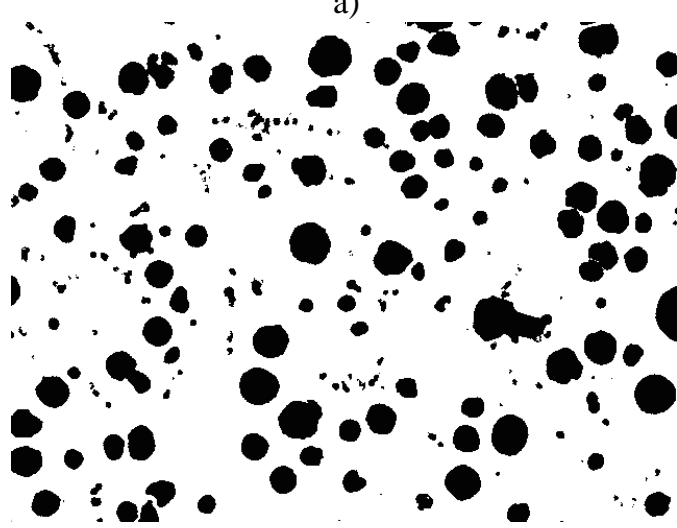

c)

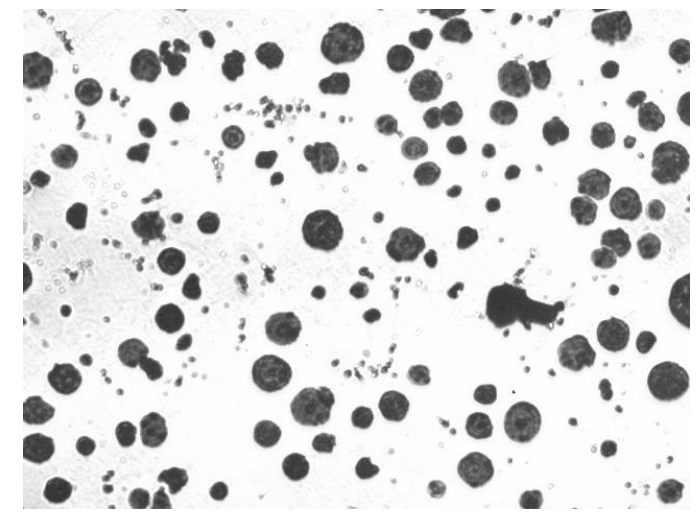

b)

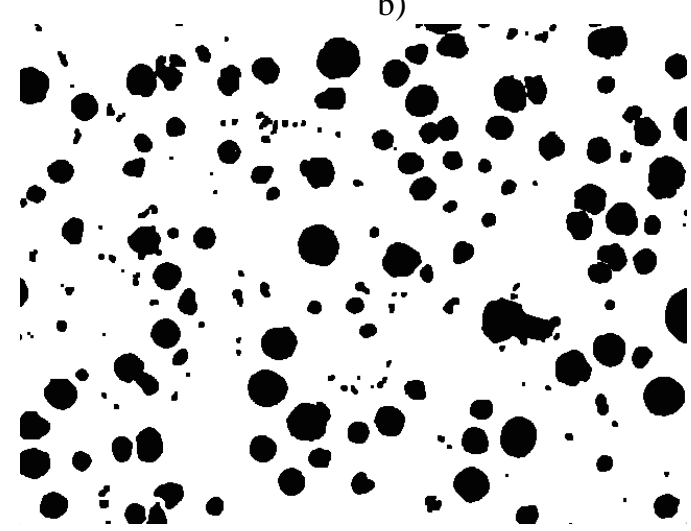

d)

Figura 7: Etapas de pré-processamento do SVC desenvolvido, em que (a) Imagem original, (b) imagem em escala de cinza e (c) imagem limiarizada por Otsu e (d) Operação morfológica de Abertura de (c) com elemento estrurante 3x3.

Após o pré-processamento, realiza-se a busca dos nódulos contidos na mesma através de uma varredura nos eixos $X$ e $Y$ da imagem de dimensões $L n$ x $C n$ pixels, através do método Crescimento de Região. A Figura 8 ilustra a metodologia deste método, que é explicada a seguir.

O crescimento por agregação de pixels, utilizado neste trabalho, é o mais simples de ser implementado. Nele inicia-se por um conjunto de pontos, chamado de semente, e a partir desta, a região cresce anexando a cada ponto somente aqueles pixels que possuam propriedades similares, como nível de cinza, cor, entre outras. Este método de segmentação agrupa pixels ou sub-regiões em regiões maiores [16]. De acordo com Rebouças 
Filho [17], nesta técnica, para um pixel ser agregado à região é necessário que este esteja na vizinhança da mesma e que obedeça a um critério pré-estabelecido. Este, geralmente, baseia-se em parâmetros pré-definidos, como intensidade de tom de cinza, média de tom de cinza na região, entre outros.

Ao aplicar a Limiarização, todos os objetos de interesse estão na cor preta e o fundo está branco. Deste modo, quando um objeto preto é detectado, uma semente é criada naquele pixel. A partir da semente, a região cresce até estabilizar, estado em que o objeto foi totalmente segmentado. Após segmentar cada objeto, a varredura continua procurando novos objetos. Vale ressaltar, que apenas objetos novos são contabilizados para incrementar a contagem dos objetos.

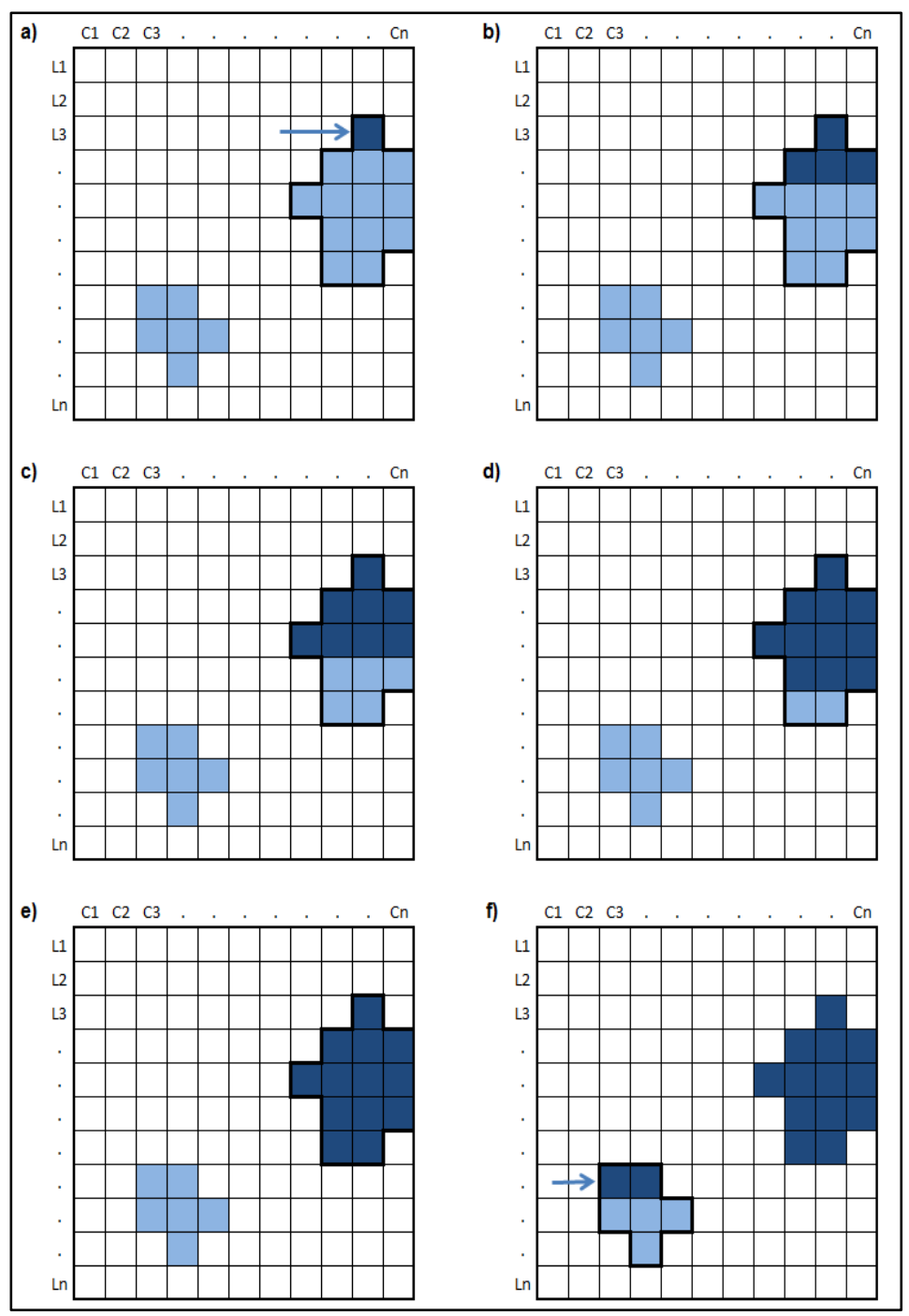

Figura 8: Segmentação de um nódulo de grafita, em que (a) Detecção da semente, (b, c, d) crescimento de região, (e) detecção final do objeto e (f) detecção da semente de um novo objeto.

Ao fim da varredura em toda a imagem tem-se o próximo passo é o cálculo da densidade de nódulos das amostras, de acordo com a norma técnica NBR 6913 MB-1512 da ABNT [8]. Após encontrar os nódulos, verifica-se se os mesmos estão nas bordas da imagem ou não, e caso esteja nas extremidades da imagem este é contabilizado como Nódulo Parcial (NP), os outros que estão inteiramente dentro da imagem são contabilizados como Nódulos Inteiros (NI).

O resultado do cálculo da densidade das amostras é apresentado conforme ilustrado na Figura 9. Além da densidade, é apresentada a quantidade de nódulos na periferia e no interior de cada amostra. 


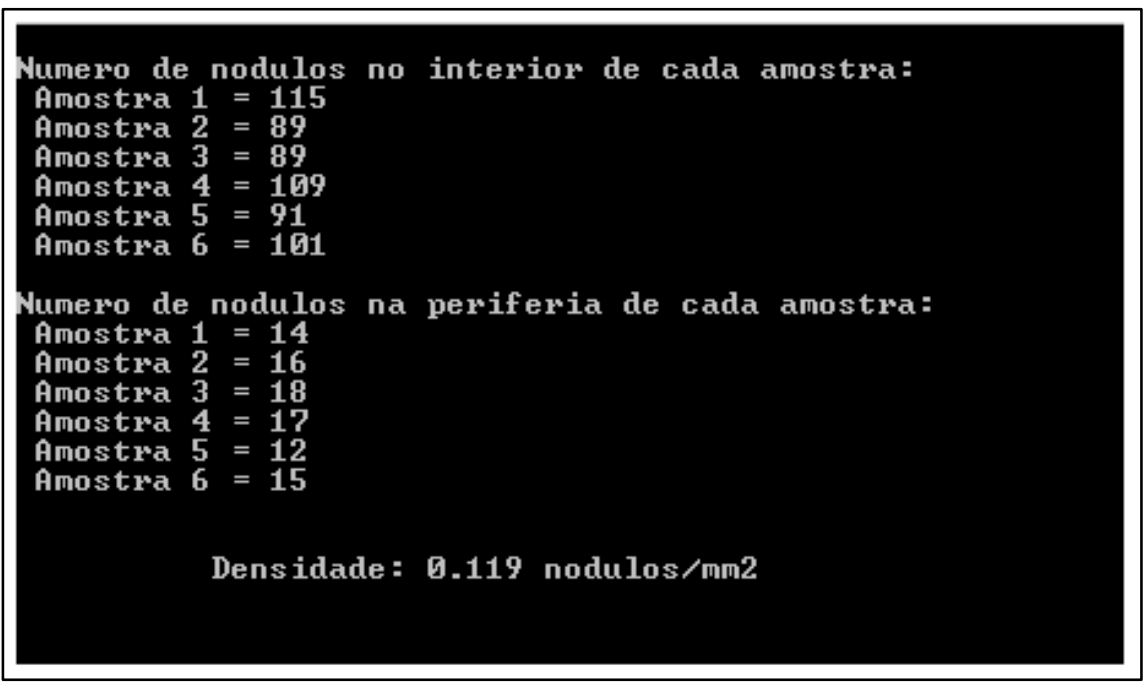

Figura 9: Resultados obtidos com o software.

\section{RESULTADOS}

Após a implementação do software foi possível realizar a contagem dos nódulos de grafita computacionalmente e comparar os dois métodos de contagem: Tradicional e Computacional.

Para contagem pelo método tradicional foram realizadas 6 contagens, independentes, dos nódulos em seis regiões distintas da amostra através de um microscópio numa escala de 200X. O tempo médio da contagem de cada amostra foi de $1 \mathrm{~min} 47 \mathrm{seg}$ pelo método tradicional. Como no trabalho são realizadas contagens em 6 amostras tem-se um tempo total aproximado de 11 minutos.

Após as contagens, foram realizados os cálculos de densidade de nódulos de grafita para cada uma das seis contagens, para uma comparação com a posterior contagem através do software, a fim de comprovar a eficiência do método computacional de contagem em relação ao método tradicional, conforme pode ser visto na Tabela 1.

Tabela 1: Contagem dos nódulos através do método tradicional.

\begin{tabular}{|c|c|c|c|c|c|c|c|c|c|c|c|c|}
\hline \multirow{2}{*}{$\begin{array}{l}\text { NÚMERO DA } \\
\text { CONTAGEM } \\
\text { AMOSTRA N }\end{array}$} & \multicolumn{2}{|c|}{$1^{A}$} & \multicolumn{2}{|c|}{$2^{A}$} & \multicolumn{2}{|c|}{$3^{A}$} & \multicolumn{2}{|c|}{$4^{\mathrm{A}}$} & \multicolumn{2}{|c|}{$5^{A}$} & \multicolumn{2}{|c|}{$6^{A}$} \\
\hline & NI & NP & NI & NP & NI & NP & NI & NP & NI & NP & NI & NP \\
\hline $\mathrm{N}=1$ & 99 & 19 & 105 & 17 & 101 & 17 & 100 & 17 & 101 & 17 & 98 & 19 \\
\hline $\mathrm{N}=2$ & 94 & 18 & 96 & 17 & 94 & 19 & 89 & 17 & 84 & 18 & 94 & 18 \\
\hline $\mathrm{N}=3$ & 82 & 18 & 77 & 18 & 87 & 19 & 82 & 19 & 80 & 18 & 83 & 18 \\
\hline $\mathrm{N}=4$ & 92 & 20 & 93 & 22 & 84 & 21 & 97 & 20 & 94 & 22 & 98 & 20 \\
\hline $\mathrm{N}=5$ & 95 & 14 & 90 & 13 & 86 & 14 & 89 & 13 & 90 & 14 & 92 & 14 \\
\hline $\mathrm{N}=6$ & 88 & 13 & 89 & 14 & 82 & 17 & 88 & 15 & 89 & 13 & 92 & 17 \\
\hline $\begin{array}{l}\text { Densidade } \\
\left(\text { nódulos } / \mathrm{mm}^{2} \text { ) }\right.\end{array}$ & \multicolumn{2}{|c|}{0,111} & \multicolumn{2}{|c|}{0,111} & \multicolumn{2}{|c|}{0,109} & \multicolumn{2}{|c|}{0,110} & \multicolumn{2}{|c|}{0,109} & \multicolumn{2}{|c|}{0,113} \\
\hline Densidade média & \multicolumn{12}{|c|}{0,110 nódulos $/ \mathrm{mm}^{2}$} \\
\hline
\end{tabular}

Com a implementação dos Sistemas de Visão Computacionais propostos foi possível realizar a contagem dos nódulos de grafita em cada amostra sem a necessidade de contá-los visualmente, amostra por amostra, o que acelerou o processo, em que os dois métodos demoraram aproximadamente 6 segundos para contabilizar os nódulos em todas as imagens, isto para ambos os métodos propostos. A Tabela 2 apresenta o resultado das 
contagens nas seis amostras, assim como o resultado do cálculo da densidade, através dos métodos computacionais propostos.

Tabela 2: Contagem dos nódulos através dos métodos computacionais desenvolvidos utilizando os métodos Watershed e Crescimento de Regiões.

\begin{tabular}{l|c|c|c|c}
\hline \multirow{2}{*}{ AMOSTRA N } & \multicolumn{2}{|c|}{$\begin{array}{c}\text { RESULTADO DA CONTAGEM COM } \\
\text { WATERSHED }\end{array}$} & \multicolumn{2}{c}{$\begin{array}{c}\text { RESULTADO DA CONTAGEM COM } \\
\text { CRESCIMENTO DE REGIÕES }\end{array}$} \\
\cline { 2 - 5 } & NI & NP & NI & NP \\
\hline $\mathrm{N}=1$ & 115 & 14 & 107 & 14 \\
\hline $\mathrm{N}=2$ & 89 & 16 & 85 & 10 \\
\hline $\mathrm{N}=3$ & 89 & 18 & 94 & 17 \\
\hline $\mathrm{N}=4$ & 109 & 17 & 117 & 14 \\
\hline $\mathrm{N}=5$ & 91 & 12 & 80 & 17 \\
\hline $\mathrm{N}=6$ & 101 & 15 & 107 & \\
\hline $\begin{array}{l}\text { Densidade } \\
\text { (nódulos } / \mathrm{mm}^{2} \text { ) }\end{array}$ & 0,119 & & 0,117 \\
\hline
\end{tabular}

\section{DISCUSSÃO}

Após aplicar os métodos Watershed e Crescimento de Regiões nas amostras para contagem de nódulo de grafita, torna-se possível uma avaliação mais detalhada utilizando as contagens dos especialistas como padrão. Neste sentido, a Tabela 3 compara os valores individuais obtidos por cada especialista com os resultados obtidos pelos sistemas propostos através dos desvios individuais e padrão.

Tabela 3: Comparação entre os cálculos de densidade através dos métodos tradicional e computacional.

\begin{tabular}{|c|c|c|c|c|c|c|c|}
\hline \multirow{2}{*}{\multicolumn{2}{|c|}{$\begin{array}{c}\text { CÁLCULO } \\
\text { TRADICIONAL }\end{array}$}} & \multicolumn{3}{|c|}{$\begin{array}{c}\text { SVC COM } \\
\text { WATERSHED }\end{array}$} & \multicolumn{3}{|c|}{$\begin{array}{c}\text { SVC COM } \\
\text { CRESCIMENTO DE REGIÕES }\end{array}$} \\
\hline & & DENSIDADE & DESVIOS & DESVIO & DENSIDADE & DESVIOS & DESVIO \\
\hline $1^{\mathrm{a}}$ Contagem & 0,111 & \multirow{6}{*}{0,119} & 0,008 & \multirow{6}{*}{0,0087} & \multirow{6}{*}{0,117} & 0,005 & \multirow{6}{*}{0,0061} \\
\hline $2^{\mathrm{a}}$ Contagem & 0,111 & & 0,008 & & & 0,005 & \\
\hline $3^{\text {a }}$ Contagem & 0,109 & & 0,010 & & & 0,008 & \\
\hline $4^{\mathrm{a}}$ Contagem & 0,110 & & 0,009 & & & 0,007 & \\
\hline $5^{\text {a Contagem }}$ & 0,109 & & 0,010 & & & 0,008 & \\
\hline $6^{\text {a }}$ Contagem & 0,113 & & 0,007 & & & 0,004 & \\
\hline
\end{tabular}

Analisando a Tabela 3, percebe-se que o método Crescimento de Regiões obtém um melhor resultado que o método Watershed considerando a densidade obtida por cada método e seus respectivos desvios padrões. Isto acontece principalmente pela etapa de Pré-processamento utilizada para este sistema, visto que ele possui certas limitações em sua definição, então faz-se necessário retirar problemas de luminosidade e imperfeições quanto à textura do fundo da amostra utilizando o limiar de Otsu, além de retirar pequenas estruturas com a operação de Abertura da Morfologia Matemática.

O método Watershed em sua definição se apresenta robusto a estas falhas, mas em alguns nódulos isto afeta os resultados obtidos, visto que dentro do nódulo pode existir alguma borda pequena que será detectada pelo método como dois nódulos gerando uma contagem errada, além disto pequenos objetos também serão contabilizados e por fim, falhas de luminosidades pode ocasionar diferenças na configuração do método Wa- 
tershed, quanto à quantidade de água à ser jogada dentro de cada bacia hidrográfica, o que representa na implementação quanto a região irá crescer e onde ela irá parar, já que um limiar deve definir este valor de crescimento.

Quanto ao tempo de análise, os métodos propostos apresentam sua grande vantagem, visto que demoram aproximadamente 1 segundo para cada imagem, que totalizam 6 segundos para todas as imagens, enquanto o método convencional demora aproximadamente 640 segundos para todas as imagens. Vale à pena ressaltar que as imagens utilizadas possuem tamanho 640x480, e caso fossem usadas imagens com maior resolução, este tempo iria aumentar na mesma proporção da imagem, mas isto teria um bom custo benefício já que os nódulos ficariam mais nítidos.

Os tamanhos da imagem onde serão aplicados métodos de PDI afetam diretamente o custo computacional em aplicações com Sistemas de Visão Computacional, visto que a área analisada e percorrida pelos métodos aumenta na mesma proporção da imagem [8]. Ambos os métodos implementados funcionam através da análise da vizinhança dos pixels, em que foi usado a máscara $3 \times 3$ para ambos os métodos. Caso esta máscara também seja maior, cada pixel analisado também irá demandar mais tempo, gerando uma análise de imagem mais lenta [17].

\section{CONCLUSÕES}

O método tradicional de contagem de nódulos possui como característica ser um processo custoso e muitas vezes não tão confiável devido à fadiga do operador após análise de muitas imagens. Com o intuito de melhorar o método de contagem foi desenvolvido dois sistemas de visão computacional para realizar esta operação de forma automática.

Os softwares desenvolvidos atenderam as expectativas gerando resultados satisfatórios e permitindo a produção de análises sobre a densidade de nódulos das amostras de forma automática. Os softwares demonstraram ser mais confiáveis que a contagem tradicional, devido existir alta possibilidade de existir erro por parte do operador durante a contagem pelo método tradicional e também mais rápido conforme verificado na análise dos resultados.

Dentre os métodos utilizados, observou-se superioridade do método Crescimento de Regiões em relação à transformada Watershed, visto que foi mais robusto à falhas, apresentando menores erros.

Uma sugestão para futuros trabalhos seria aplicar técnicas de Reconhecimento de Padrões para validar os nódulos encontrados antes de contabilizar os mesmos. Além disto, será desenvolvida uma interface amigável para que pessoas de outras áreas possam usar com facilidade os softwares desenvolvidos.

\section{AGRADECIMENTOS}

Os autores do trabalho agradecem ao Laboratório de Protótipos do IFCE campus Maracanaú e ao Grupo de Pesquisa de Sistemas Inteligentes pelo auxílio e apoio no desenvolvimento deste projeto.

\section{BIBLIOGRAFIA}

[1] RÉZIO, Ana C. C.. Reconhecimento e Rastreamento de Objetos, Trabalho de Conclusão de Curso, Ciência da Computação, Universidade Católica de Goiás, 2008.

[2] REIS JÚNIOR, Ademar de S.; SOARES FILHO, Milton. Aplicações de Processamento de Imagens a Sistemas de Segurança, Trabalho de Conclusão de Curso, Ciência da Computação, Universidade Federal do Paraná, 2002.

[3] ALBUQUERQUE, Victor H. C. de., TAVARES, João M. R. S., CORTEZ, Paulo C., et al., Ferramenta de Análise Não Destrutiva para Obtenção de Parâmetros Microestruturais Baseada em Visão Computacional, CIBIM, Porto, 2011.

[4] CHIAVERINI, Vicente. Aços e Ferros Fundidos, 5ed., São Paulo, Associação Brasileira de Metais - ABM, 1982

[5] MELlO, Carlos A. T. de. Vida em Fadiga de um Ferro Fundido Nodular Ferrítico com Variações Microestruturais, Dissertação de Mestrado, Engenharia Metalúrgica , Pontifícia Universidade Católica, Rio de Janeiro, 2003. 
[6] CALLISTER, William D. Jr. Ciência e Engenharia de Materiais: Uma introdução, 5 ed., Rio de Janeiro, LTC, 2000.

[7] FEISTE, K. L., REIMCHE, W., BACH, Fr. W., et al., Caracterização das propriedades mecânicas de ferro fundido nodular por análise harmônica dos sinais das correntes parasitas, Rio de Janeiro, $6^{\mathrm{a}}$ Conferência sobre Tecnologia de Equipamentos, 2002.

[8] ASSOCIAÇÃO BRASILEIRA DE NORMAS TÉCNICAS. NBR 6913: Ferro fundido nodular e ferro fundido maleável - Contagem de nódulos de grafita, Rio de Janeiro, 1990.

[9] BELAID, Lamia Jaafar., MOROU, Walid,. Image Segmentation: a watershed transformation . Image Anal Stereol, v. 28, pp. 93-102, 2009.

[10] CHEN, Qing; YANG, Xiaoli; PETRIU, Emil M., Watershed Segmentation for Binary Images with Different Distance Transforms, In: The 3rd IEEE International Workshop on Haptic, Audio and Visual Environments and Their Applications, 2004.

[11] GONZALEZ, Rafael C., WOODS, Richard E. Processamento de imagens digitais, 1 ed., São Paulo, Edgar Blücher, 2000.

[12] SCURI, Antônio E., Fundamentos da Imagem Digital, Rio de Janeiro, 2002.

[13] BRADSKI, Gary; KAEHLER, Adrian. Learning OpenCV., 1 ed., Estados Unidos: O’Reilly Media, 2008.

[14] MARENGONI, Maurício; STRINGHINI, Denise. Tutorial: Introdução à Visão Computacional usando OpenCV, Universidade Presbiteriana Mackenzie, 2009.

[15] STEMMER, Marcelo R., ORTH, Alexandre, ROLOFF, Mário L., et al., Sistemas de Visão, Florianópolis, 2005.

[16] NUNES, Fátima L. S. Introdução ao Processamento de Imagens Médicas para Auxílio ao Diagnóstico Uma Visão Prática, [s.1.], 2006.

[17] REBOUÇAS FILHO, Pedro Pedrosa., CORTEZ, Paulo Cesar., ALBUQUERQUE, Victor Hugo C., "3D segmentation and visualization of lung and its structures using CT images of the thorax", Journal of Biomedical Science and Engineering, v. 6, pp. 1099-1108, 2013. 